\title{
Por que se explicar? A normalidade construída por meio da linguagem no consultório oncológico ${ }^{1}$
}

\author{
Joseane Souza $a^{a}$ \\ Ana Cristina Ostermann ${ }^{b}$
}

\footnotetext{
1 Agradecemos à CAPES pelo apoio obtido por meio de bolsas de Doutorado e de Pós-Doutorado concedidas à primeira autora, e também ao $\mathrm{CNPq}$, à $\mathrm{CA}$ PES e à FAPERGS pelo apoio obtido através de Bolsa de Produtividade (Processo CNPq n. ${ }^{\circ}$ 311473/2012-1) e pelos auxílios à pesquisa obtidos através dos editais $\mathrm{MCT} / \mathrm{CNPq} / \mathrm{MEC}$ (Processo n. $\left.{ }^{\circ} 401569 / 2010-1\right)$ e PPSUS MS/CNPq/ FAPERGS 06/2006 (Processo $n^{\circ} .^{0}$ 0700767) à segunda autora.
}

\begin{abstract}
Resumo
Este artigo analisa a atividade de prestação de contas, ou accounts, que, por sua vez, circunscreve ações (formas de agir por meio da fala-em-interação) realizadas por uma paciente com câncer de mama quando em consulta de revisão com seu oncologista. Os dados aqui analisados fazem parte de um corpus de 20 consultas gravadas em áudio nos anos de 2012 e 2014 entre oncologistas e pacientes com câncer de mama em um hospital privado da região sul do Brasil. As interações foram transcritas e analisadas a partir das abordagens teórico-metodológicas da Análise da Conversa e das Categorias de Pertença (SACKS, 1992). A linha argumentativa central do artigo consiste em demonstrar como as prestações de contas produzidas pela paciente transformam (no sentido de renovar) o contexto interacional, ao solicitarem uma afiliação do médico e, assim, construírem a normalidade da situação experienciada pela paciente. A análise sequencial evidencia as ações sociais e consequências interacionais que uma narrativa não solicitada pode gerar não apenas para o contexto sequencial, mas também para o reestabelecimento e a reconstituição da normalidade e da ordem moral, de forma mais larga.
\end{abstract}

Palavras-chave: consultas oncológicas; prestação de contas; normalidade; moralidade, narrativas.

Recebido em 30 de novembro de 2015 Aceito em 30 de março de 2016

\footnotetext{
${ }^{a}$ Colaboradora em pós-doutorado no Programa de Pós-Graduação em Linguística Aplicada da UNISINOS, joseanedesouzabr@gmail.com

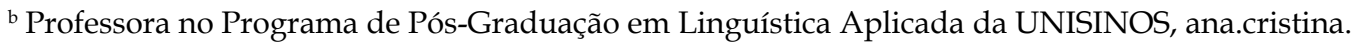
ostermann@gmail.com
} 


\section{Introdução}

Neste artigo, analisa-se a atividade de prestação de contas, ou accounts, que, por sua vez, circunscreve ações (entendidas aqui como formas de agir por meio da fala-eminteração) realizadas por uma paciente com câncer de mama em uma consulta de revisão com seu oncologista. A linha argumentativa central do artigo consiste em demonstrar como as prestações de contas produzidas pela paciente transformam (no sentido de renovar) o contexto interacional, ao de certa forma solicitarem uma afiliação do médico, e, assim, constroem a normalidade da situação experienciada pela paciente. A relação entre o fenômeno interacional em questão e os estudos da linguagem encontra-se, neste artigo, no fato de a atividade de prestação de contas acontecer por meio de uma narrativa aparentemente não requisitada pelo interlocutor, nesse caso, o oncologista. Ou seja, demonstramos, a partir da análise sequencial, as ações sociais e consequências interacionais que uma narrativa não solicitada pode acarretar não apenas para uma interação singular, mas também para reestabelecer e reconstituir a normalidade e a ordem moral, de forma mais larga. Assim, nas seções seguintes, mostraremos o caminho percorrido para se chegar ao entendimento do fenômeno.

Além disso, a interação aqui analisada advém de um projeto de pesquisa maior, ${ }^{2}$ que abrange consultas entre pacientes com câncer de mama e seus oncologistas. Todas são consultas de acompanhamento e revisão. Essa seleção explica-se por um dos objetivos da pesquisa, que é o de problematizar a lacuna nos estudos brasileiros que tratam da comunicação médico-paciente no câncer, uma vez que tais estudos concentram-se na observação de dois extremos: ou no momento da comunicação das más notícias, ou nos desdobramentos comunicacionais na situação de pacientes terminais, conforme explicitado também em Souza (2015).

Na próxima seção resgatamos brevemente a literatura

Projeto de pesquisa $A$ construção de tópicos delicados na fala-em-interação em consultas oncológicas. sobre prestação de contas, sua relação com a estrutura e o papel das narrativas e a possível relação entre prestação de contas, construção da normalidade e orientação dos interagentes à ordem moral. 


\section{Uma "inocente" narrativa não solicitada? Prestação de contas, normalidade e moralidade nas interações sociais}

Del Corona e Ostermann (2013) asseguram que, em um contexto interacional, narrativas "não são pacotes necessariamente ordenados, coesos e cuidadosamente organizados em sua temporalidade e cronologia" (p. 181), já que as histórias são construídas turno a turno e com a participação dos interagentes envolvidos na atividade.

No artigo de Labov (1997 [2007]), o autor difere o evento contação de histórias do fenômeno narrativas de experiência pessoal, argumentando que, para existirem, as narrativas de experiência pessoal necessitam de um tratamento do interlocutor diferente da contação de histórias. As narrativas de experiência pessoal requerem um espaço concedido para o falante poder realizálas. Ou seja: o sistema de tomada de turnos é reorganizado nas narrativas, de forma que "a compleição bem-sucedida da narrativa requer reatribuições automáticas do papel de falante ao narrador após o turno seguinte de uma fala, se a narrativa não for completada naquele turno" (LABOV, 1997, p. 9). Dessa forma, observa-se que a perspectiva da Análise da Conversa está intrinsecamente preocupada com as ações que as narrativas desempenham nas interações, justamente entendendo essas narrativas como eventos coconstruídos pelos participantes. As narrativas relacionam-se ao próximo ponto, os accounts - que iremos utilizar com a tradução de prestação de contas -, pois muitas vezes é por meio da própria narrativa que as pessoas prestam contas sobre algo.

Os accounts advêm de uma noção etnometodológica, a accountability, e, portanto, são vistos como uma propriedade do mundo social. Conforme Coulon (1995), essa propriedade tem a ver com o fato de o mundo ser descritível, analisável, relatável e inteligível. Pela perspectiva da Análise da Conversa (SACKS; SCHEGLOFF; JEFFERSON, 1974), proveniente da etnometodologia, Heritage (1988) define accounts como situações nas quais os interagentes proveem uma explicação, justificativa ou, para usar uma expressão mais generalizadora e que dá origem à tradução aqui utilizada, uma prestação de contas sobre o que estão fazendo em termos de razões ou motivos. $\mathrm{Na}$ atividade de prestar contas, com as ações de explicar-se ou justificar-se, há uma demonstração do processo 
3 Stivers (2008) entende que o termo afiliação deve ser usado para descrever ações em segunda posição (normalmente em resposta) que dão suporte ao posicionamento ou ponto de vista do interlocutor. Para Steensig (2012), turnos afiliativos em segunda posição são os que (a) demonstram empatia, (b) oferecem suporte a posicionamentos, e (c) mostram-se colaborativos com a preferência das ações. Ver também Lindström e Sorjonem (2013). Para uma discussão mais aprofundada sobre afiliação nos dados sob análise, ver Souza (2015). Ao mesmo tempo, solidariedade social é um princípio que está ainda mais ligado à prestação de contas. Heritage (1984), concordando com Pomerantz (1984), observa que os ouvintes de uma explicação ou justificativa normalmente evitam discordar dessas produções, ou "seguram" suas discordâncias para que sobre eles não se impute uma falta de solidariedade social (HERITAGE, 1984, p. 219). de análise contínua das pessoas sobre suas próprias ações e também sobre possíveis ações do outro.

Segundo Pedro Garcez (2008), a accountability - traduzida também como explicabilidade - é um elemento normativo situado que se pode observar na produção de conduta dos membros; assim,

[A]s ações de prestação de contas seriam explicitações disso, necessárias quando pode haver dúvida quanto ao caráter racional, razoável da conduta de um membro. Isto é, quando os participantes avaliam que podem pairar dúvidas sobre a propriedade do que eles estão dizendo/fazendo, observa-se que eles efetivamente 'se explicam', prestam contas da sua conduta, mediante ações como justificativas, pedidos de desculpas e explicações, entre outras. Tais ações revelam o caráter da análise que os participantes estão constantemente fazendo das suas próprias ações e das ações uns dos outros [...]. (2008, p. 27)

Buttny e Morris (2001) reportam a vasta produtividade do conceito de account na literatura. Os autores explicam que a distinção mais prática é a que diferencia os accounts por ações - no sentido de responder a uma conduta problemática - de accounts de ações - que envolve uma descrição ou uma narrativa de eventos, sem necessariamente lidar com algum suposto problema ou conduta problemática. De acordo com os autores, as duas abordagens lidam com um interesse comum: como os interagentes apresentam a sua perspectiva, "o seu lado da história", ou seja, "como interpretam e reconstroem retoricamente os eventos através da fala" (BUTTNY; MORRIS, 2001, p. 286). Os autores lembram que a partir do artigo de Scott e Lyman de 1968, a abordagem dos accounts por ações foi a que mais se desenvolveu e é a que ocupa maior espaço nos estudos atualmente.

No que tange ao interesse deste artigo, contudo, os accounts encontrados nos dados da coleção maior da qual este artigo se origina parecem mais com narrativas quando não está posto nenhum problema na interação até então, nenhuma conduta problemática. Assim, por meio desses accounts, o falante está de fato a produzir o contexto local dali por diante, estipulando um tópico ou uma agenda, requerendo determinada orientação do interlocutor, ou criando relevâncias interacionais nas quais ações como concordância (em um nível mais estrutural) ou afiliação ${ }^{3}$ (em um nível de solidariedade social) se fazem preferencialmente requeridas, por exemplo. 
Alan Firth (1995) problematiza justamente esse superdesenvolvimento de estudos que se ocupam dos accounts que respondem a alguma conduta problemática prévia na interação. $\mathrm{O}$ autor acredita que há a necessidade de se olhar para os accounts mais (con)sequencialmente, mais prospectivamente, como algo que vai influenciar o contexto local (especialmente o contexto interacional) subsequente, e não apenas que lida com o contexto anterior. $O$ autor exemplifica, citando a natureza do trabalho de Hewitt e Stokes (1975), que olha para a maneira como "desculpas ou justificativas são proferidas prospectivamente, na antecipação de uma ação vindoura não-afiliativa ou de alguma forma problemática" (1975 apud FIRTH, 1995, p. 202). Por meio de seu trabalho sobre práticas utilizadas nas negociações de vendas entre uma organização e seus clientes - por telefone e telex -, Firth ocupase então em lidar não tanto com a natureza de restauração ou reparo possivelmente contida nos accounts, mas com a mudança que um account pode gerar nas circunstâncias da interação. Ele chama esse aspecto de "característica criativa de resolução de problemas dos accounts".

Além disso, a literatura sobre accounts mostra uma clara relação entre a produção de justificativas e o trabalho moral (DREW, 1998) realizado em dado contexto. É neste ponto que o trabalho maior da prestação de contas observada nos dados aqui analisados - a construção de determinada normalidade - encontra também a orientação à moralidade, mais especificamente, no que tange ao uso de psicotrópicos. Gabe, Coveney e Williams (2015) realizaram um estudo a respeito de como as pessoas entendem e negociam o uso ou não-uso de hipnóticos (psicotrópicos utilizados para dormir e que podem causar dependência física ou psíquica) em vários grupos focais no Reino Unido que têm em comum o assunto do gerenciamento do sono. Nas opiniões e descrições dos membros desse grupo, os pesquisadores encontraram repertórios morais que perpassam aspectos como vício e controle, que vão desde o usuário adito até aquele que revela nunca ter usado nem querer usar medicamento para dormir. Em parte respaldadas pelos achados de Gabe, Coveney e Williams (2015), especula-se aqui a possibilidade de a paciente em questão, nos dados analisados no presente artigo, associar o uso de um antidepressivo a uma fraqueza emocional - como a adição seria no caso do remédio 
4 Sobre preferência e despreferência, conceitos de base da Análise da Conversa, ver o capítulo de Pomerantz (1984) e também o verbete ação preferida / ação despreferida (SOUZA; OSTERMANN, 2012). para dormir -, revelando assim um repertório moral, conforme o estudo citado, o que será retomado na discussão final.

Laura Sterponi (2003) descreve accounts que remedeiam uma conduta problemática, de ordem moral, de membros de famílias conversando à mesa de jantar. A autora explica que o conceito de moralidade pode ser melhor entendido quando visto por meio dos accounts, ou accountability, como uma atividade situada e sequencial, que indicializa preferências relativas à "ordem social e à ideologia moral" (2003, p. 80). Sterponi, dentro de uma discussão bem mais ampla sobre a relação entre moralidade e accounts, afirma que a visão da psicologia considera a moralidade (ou o desenvolvimento moral) como um processo cognitivo, pertencente à seara individual, e que as metodologias daquela área (entrevistas ou experimentos em laboratório), justamente por centrarem-se no individual e não necessariamente contemplarem o social, acabam não investigando como os accounts dos falantes são produzidos ou como são organizados sequencialmente, e principalmente em suas ocorrências nas interações reais cotidianas. Alinhadas com a perspectiva de Sterponi (2003), também aqui defendemos que são as interações reais cotidianas o lócus primordial em que as pessoas fazem ou atualizam a moralidade no aqui-e-agora.

Sterponi (2003) retoma que os accounts são largamente tratados pela Análise da Conversa como segundas partes em um par adjacente e caracterizam ações (ou segundas partes, nesse caso) despreferidas ${ }^{4}$. Porém, como explicado anteriormente, o interesse desta análise não é somente no que Schegloff (2007) aponta como retrossequências, que é o caso dos accounts que remediam algo, mas muito mais em como esses accounts geram a organização local na interação (e os entendimentos dos interagentes) de forma prospectiva, também construindo e atualizando normalidade e moralidade situadamente.

Como dito anteriormente, os accounts neste estudo acontecem por meio de narrativas instauradas nas interações. Anna De Fina (2009) trata do estudo das narrativas em entrevistas e considera os accounts justamente um gênero de narrativa que desempenha a ação de justificativa pelos seus falantes. No presente estudo, nota-se que a narrativa carrega explicações da paciente que está na atividade de prestar contas - voluntariamente - sobre o uso de um medicamento. 
Como se pode ver, há uma forte relação entre a produção das narrativas e a construção da normalidade. O próprio fundador da Análise da Conversa, Harvey Sacks, já discorrera sobre tal ligação em suas observações das conversas mundanas, tema de suas aulas:

\begin{abstract}
É incrível como, em conversas comuns, as pessoas, ao relatarem algum fato, relatam aquilo que podemos ver que aconteceu, não o que aconteceu, mas a normalidade do que aconteceu. Os relatos não se prendem muito a cenas, atividades, participantes, mas anunciam a normalidade do fato, o fato de ser comum. [...] Se expandirmos a analogia do que obviamente chamamos de trabalho - qualquer coisa que exija energia analítica, intelectual, emocional - então seremos capazes de ver que todo tipo de coisas normalizadas, por exemplo, características pessoais e coisas desse tipo, são tarefas desempenhadas, que precisam de um tipo de esforço, de treinamento, e assim por diante. (1984 [2007], tradução de Portela, Pellegrino e Gomes, grifo das autoras, p. 167)
\end{abstract}

Construção de normalidade ou orientação à moralidade, a questão é que a observação da prestação de contas nas narrativas não solicitadas é um meio produtivo para se acessar os entendimentos e negociações dos falantes sobre seu conhecimento dos valores do mundo social compartilhados no aqui-e-agora. A título de exemplo, a pesquisa de Denvir (2012) investiga meios pelos quais pacientes produzem seus pontos de vista sobre sua conduta ser normal/saudável a respeito do uso do álcool. O autor observa que "voluntariar detalhes normalizadores" é uma das maneiras de os pacientes produzirem suas descrições sobre o uso e de descreverem-se como "moderados, autodisciplinados ou conscientes sobre a sua saúde" (2012, p. 1654). Antes de passarmos à análise interacional, trataremos da metodologia utilizada neste estudo.

5 Algumas das interações foram transcritas pelas bolsistas do grupo de pesquisa Fala-em-Interação em Contextos Institucionais e Não-Institucionais, coordenado pela segunda autora, em 2012, e então revisadas várias vezes pela primeira autora ao longo dos anos de 2013 a 2015.

\section{Metodologia}

Os dados utilizados neste artigo são naturalísticos. As interações das vinte consultas médicas de acompanhamento e revisão entre oncologistas e pacientes com câncer de mama foram coletadas em um hospital da rede privada da região sul do Brasil por meio de gravação em áudio e depois transcritas seguindo as convenções da área (JEFFERSON, 1984) ${ }^{5}$. Uma tabela com a versão resumida dessas convenções é apresentada na Figura 1, a seguir. 
Figura 1 - Convenções de transcrição, adaptadas de Jefferson (1984)

\begin{tabular}{|cc|}
\hline [texto] & Falas sobrepostas \\
\hline$(1.8)$ & Pausa \\
\hline$()$. & Micropausa \\
\hline, & Entonação contínua \\
\hline$\cdot$ & Entonação descendente do turno \\
\hline$?$ & Entonação ascendente do turno \\
\hline$:$ & Alongamento de som \\
\hline TEXTO & Fala com volume mais alto \\
\hline Texto & Sílaba, palavra ou som acentuado \\
\hline (texto) & Dúvida na transcrição \\
\hline XXXX & Texto inaudível \\
\hline$($ texto)) & Comentários da transcritora \\
\hline haha & Risada \\
\hline otexto & Fala em volume mais baixo \\
\hline ootexto ${ }^{\circ}$ & Fala em volume muito baixo \\
\hline$\uparrow$ & Entonação ascendente da sílaba \\
\hline$\downarrow$ & Entonação descendente da sílaba \\
\hline$>$ texto< & Trecho de fala mais rápida \\
\hline- & Interrupção abrupta da própria fala \\
\hline$=$ & Fala colada \\
\hline $\mathrm{h}$ & Expiração audível \\
\hline $\mathrm{h}$ & Inspiração audível \\
\hline
\end{tabular}

6 O projeto de pesquisa tramitou em dois comitês de ética, o da instituição pesquisada e o da instituição de ensino superior à qual as autoras estão vinculadas (homologações números 493/11 e 11/128, respectivamente).
Salienta-se que o projeto de pesquisa maior do qual este artigo deriva tramitou por dois comitês de ética (o da universidade e o da instituição pesquisada ${ }^{6}$ ). Os dados foram analisados pelo viés teórico-analítico da Análise da Conversa, doravante AC (SACKS, 1992), ou Análise da Fala-em-Interação (DREW; HERITAGE, 1992).

A AC é a abordagem utilizada quando se quer investigar como as pessoas constroem suas ações nas interações mundanas ou institucionais, como se entendem (e se fazem entender) e como se orientam para normas socialmente construídas. Parte-se da análise sequencial da fala para ver os entendimentos que são construídos pelos interlocutores. Nesta visão, cada novo turno de fala carrega o entendimento que a pessoa que o produziu tem da última fala de seu interlocutor, e assim sucessivamente, numa maquinaria que consiste em uma troca de turnos de fala. Para a AC, é na troca de turnos 
e em cada turno em si que as pessoas constroem suas ações no mundo, e o lócus dessas ações e de seus entendimentos é a própria interação.

A abordagem da $\mathrm{AC}$ não objetiva interpretar o que um participante quis dizer com determinado enunciado, mas sim presta atenção a como o outro participante (o interlocutor) demonstrou compreender esse enunciado, para então ser possível descrever suas ações. Essa premissa da sequencialidade da fala é uma das principais na $\mathrm{AC}$, e sempre relevante para qualquer estudo.

Dessa forma, pares de ações adjacentes se formam, e eles são a base do entendimento das ações para os analistas: falas concatenadas, como pedido de informação-provimento de informação, convite-recusa, convite-aceite, avaliação-avaliação, etc., permitem que o analista tome como base a ação em resposta de um falante para chegar naquilo que ele entendeu da ação do primeiro falante. As ações e os pares adjacentes vão fazendo parte de um repertório dos falantes, o que também deve influenciar na observável rapidez da coconstrução da interação.

Em estreita relação com a $\mathrm{AC}$, utilizamos também neste artigo a Análise das Categorias de Pertença (doravante ACP). A ACP preocupa-se com as descrições do mundo social produzidas pelos falantes. Essas descrições são feitas por meio de dispositivos ou métodos que "remetem à ideia de maquinaria operando por trás da ação de categorizar, da mesma forma como opera na ação de falar. Ou ainda, constituem uma espécie de matriz geradora, que possibilita aos membros fazerem descrições." (SELL; OSTERMANN, 2012, p. 135).

Sell e Ostermann (2012) lembram-nos do clássico exemplo que Sacks utiliza em duas de suas lectures (SACKS, 1992) sobre uma descrição cujas identidades dos sujeitos poderiam ser apagadas: "X chorou. Y pegou-o no colo". Questiona-se o motivo pelo qual, no caso do apagamento, as pessoas têm a propensão de entender que $X$ é um bebê e que $Y$ seria a mãe do bebê. Sacks (1992) questiona essa tendência, construindo a ideia de que então algumas atividades corresponderiam a determinadas categorias de pertencimento social - categorias que também estão circunscritas a coleções (e.g. pai - mãe - bebê etc.). Dessa forma, a atividade "chorar" está entre as atividades que determinada categoria de alguém (nesse caso "bebê") 
poderá engajar-se, e vice-versa. A explicitação dos mecanismos envolvidos na leitura do mundo que as pessoas fazem em suas falas é então o interesse na abordagem.

\section{A narrativa não solicitada sob a perspectiva interacional: a prestação de contas construindo a normalidade}

Ilustraremos nesta seção a ocorrência nos dados de um tipo de prestação de contas realizada por uma paciente em uma situação que se demonstra como interacionalmente delicada: contar ao seu oncologista que está tomando um medicamento psicotrópico não usualmente consumido por ela em um contexto em que já utiliza outros medicamentos. Os accounts formam uma sequência em que ela presta contas de seu uso, mas sem que isso tenha sido requisitado pelo médico. Há uma orientação, no conteúdo dessa sequência, tanto da parte da paciente quanto do médico, para uma reafirmação da situação como dentro da normalidade: a de que a paciente somente estaria consumindo o medicamento porque acabara de passar por um período de depressão, atribuída à carga emocional do tratamento de seu câncer de mama. Assim, essa prestação de contas constrói a normalidade dos fatos narrados pela paciente e torna relevantes próximas ações afiliativas do médico, que acabam por também operar na coconstrução dessa normalidade.

Na interação analisada a seguir, a pedido do médico, a paciente Francine descreve os medicamentos que toma atualmente, que são listados sem maiores elaborações. Contudo, adiante na interação (linha 119), ela elenca determinado medicamento de maneira diferente dos demais. Observe-se o Excerto 1.

\section{Excerto 1}

97 SILVIO:

além do fe $\uparrow$ mara tá tomando mais algum

98 medicamento

99 FRANCINE: $\uparrow a$ eu tomo um monte [né oremédio da pressão*=

100 SILVIO: [então vamos repassar toda $=$

101 FRANCINE:

mais-o]

103 SILVIO:

$$
=\circ \mathrm{e}
$$$$
=\text { ela }
$$ 
pra vê-] da press:ão,

106 FRANCINE:

é eu tomo (o q-) é- eu tomo o da tirêoide puran

108 SILVIO: te quatro, pura:n,

110 FRANCINE:

ã::: t- tomo glifage xis érre e: (.) e vytori:n,

112 SILVIO:

113 FRANCINE: que não quiseram me tirá por $\downarrow$ que ${ }^{\circ}$ eu não e[ntendi ${ }^{\mathrm{oo}}=$

114 SILVIO:

115 FRANCINE: = $\left({ }^{\mathrm{oo}}\right.$ exatamente $^{\mathrm{oo} \mathrm{o}} \mathrm{O}$ que que aconteceu, $\left.{ }^{\mathrm{o}}\right) \uparrow \mathrm{a}$ - tomo pra dormir (stilnox) né

117 SILVIO: (stilnox). é tem uma coleção mesmo ein.

118 FRANCINE: $\uparrow$ não pois tem uma coleção (0.2) e:=

119 SILVIO: =mas nenhum interage co[m o femara (viu)]

Nesse excerto, o médico realiza uma pergunta que solicita informação nas linhas 97-98, especificamente se a paciente toma mais algum medicamento além daquele sobre o qual estão tratando (em turnos anteriores não reproduzidos aqui). A paciente produz uma resposta transformativa (i.e. não produz nem o sim nem o não que a pergunta polar requer, mas uma resposta alternativa, conforme Stivers e Hayashi, 2010) que faz um ajuste sobre a quantidade de medicamentos: não seria "mais algum", como o médico sugerira com sua pergunta, mas "um monte" (linha 99). No turno seguinte, Sílvio pede que ela repasse então quais são eles. Francine lista os medicamentos sem maiores problemas, pelos seus nomes ou por suas indicações (i.e. como o da pressão arterial), com exceção de uma explicação em que ela demonstra ao médico seu status epistêmico (HERITAGE, 2012) e sua não-agentividade com relação à continuidade no uso dos medicamentos Glifage XR e Vytorin, para diabetes e para colesterol elevado, respectivamente (linhas 113 e 115). Ela também produz uma breve prestação de contas antes de listar o medicamento Stilnox, explicando que o toma para dormir (linhas 115-116). 
O próximo turno de Sílvio, então (linha 117), é uma repetição do nome desse último medicamento seguido de uma avaliação sobre a quantidade de remédios que ela toma ("é tem uma coleção mesmo ein"). Essa avaliação, com a qual Francine concorda em seu próximo turno (linha 118), afilia-se com a própria avaliação que ela já fizera no início de sua lista sobre "um monte" de medicamentos (linha 99). Nas linhas 119-120, Sílvio acrescenta uma concessão (ideia indicializada pelo "mas") à sua avaliação - apesar de muitos, nenhum desses medicamentos interage com o Femara. Com esse turno avaliativo das linhas 119-120, Sílvio também projeta um fechamento dessa sequência. Francine sobrepõe-se ao final desse turno do médico, apresentando mais um medicamento que está tomando, qual seja, Pondera, na linha 122. Veja-se a continuação da interação (retomamos novamente a linha 119 para mostrar a sobreposição de fala que marca o início do turno de Francine).

\section{Excerto 2}

119 SILVIO:

$=$ mas nenhum

120

121 FRANCINE:

122

123

124

125

126 FRANCINE:

127

128

129

130 SILVIO:

131 FRANCINE:

132 SILVIO:

133

134 FRANCINE:

135

136

137

138 SILVIO: interage co[m o femara (viu)]

[é de mar-]

de março pra cá estou tomando (es- pondera)

-eu acho que é o nome. (.) hh por- que.

†bom- eu- ã:: hhh comece:i

no- não- ã (.) \lá em se个tembro em diante

outubro em diante não sei se foi coinciłdência

que eu tava (cuidando) comecei a tê assim (.)

uma irritabilidade tão grande

ã:ham

ufe- que (ninguém) me aguentá- aguen[ta:va,

te aguentava

nem eu me aguentava ã- as- uma co:isa e eu

pa- parece assim que tudo aquilo que eu

tive que:: segurá durante o tratamento

explôdiu só- chegô. agor::a (deu)

hahaha te concedeu o::

[nem tu 
139 FRANCINE: é.=

140 SILVIO:

=a oportunidade [(também)]

141 FRANCINE: [olha:,

142 FRANCINE: é aí eu comecei a analisá a situação tava $>$ ficando difícil ficando difícil< aí eu procurei u::m (.) terapeuta.

145 SILVIO: ótimo.

146 FRANCINE: a doutora: ((nome)) (1.0) ela tem consultório aqui na na: ((nome da rua)) (1.0) e: aí: ela: fez (toda a abordagem) disse que é nor- disse bom- foi uma- é uma coisa natural depois de um

150

151 SILVIO: tratame:nto [de:ste]

152 SILVIO: [claro]= $=$ totalmente dentro do razoável

153 FRANCINE: ela disse- ela disse olha vamos fazer uma 154 coisa vamos pegar uma medicação me deu

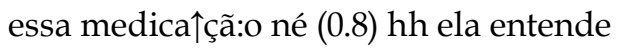
que: vai sê por tempo determina:do porque ela disse- eu não te vejo uma pessoa depressiva não te vejo isso aí é::=

160 FRANCINE: =é um período eu tô na crise que que passô .h então não eu estou indo na doutora ((nome da médica)) duas vez por mês me acalmô é o seguinte (.) eu pensei puxa vida .h março eu faço uma viagem $\uparrow$ grande $(0.8)$ e do jeito que eu tô (.) ou eu me atiro de cima do navio, (.) ou eu:: vou terminá brigando com todos companheiros hhh hah=

O formato do turno de Francine, na linha 121, assim sobreposto, parece funcionar de forma a bloquear o projeto de avaliação positiva iniciado pelo médico de que não há interação de nenhum de seus medicamentos com o Femara e também impedir que o médico leve a cabo o projeto de fechamento desse 
tópico. O medicamento em questão, Pondera, um psicotrópico antidepressivo, é produzido com ressalvas por ela. Após dizer o nome do medicamento e o período em que começara a utilizá-lo (linhas 121-122), a paciente voluntariamente inicia a produção de uma narrativa prestando contas sobre o seu uso (linhas 123-124), assim respondendo muito mais do que fora perguntado -, mais do que a questão do oncologista pedia (STIVERS; HERITAGE, 2001) - já que ele pedia apenas que ela relatasse quais eram os medicamentos que estava usando.

Por meio dessa prestação de contas, que vem explicitamente marcada pela expressão "por- que", a paciente inicia uma narrativa sobre quando começou a dar-se conta de sua irritabilidade. Note-se que há sinais de certa resistência (JEFFERSON, 1988), que o relato é interacionalmente delicado por parte de Francine, já que há pausas, alongamentos e falsos inícios (palavras que são começadas e abruptamente interrompidas por ela), ou seja, marcas de despreferência que podem ser entendidas como reveladoras de uma ação ou tópico delicado. Assim, as marcas de hesitação, a explícita conjunção explicativa "por- que" e o início que marca a construção de uma narrativa são as características do formato da prestação de contas prospectiva de Francine, que pode estar a prever um posicionamento negativo do médico a respeito de seu novo medicamento.

Francine prossegue em sua narrativa após o recebimento de um continuador pelo médico na linha 131, avaliando a própria situação e a si mesma negativamente ("ufe- que ninguém me aguentava"), o que também consiste em uma justificativa sobre por que procurou a profissional de saúde mental. Na linha 132-133, o médico produz uma avaliação de sua avaliação ("nem tu te aguentava"), que age como outro continuador para sua narrativa. Essa avaliação do médico, contudo, faz muito mais nessa interação. Ao concordar com a autoavaliação negativa produzida pela paciente, o oncologista afilia-se com o entendimento dela sobre a gravidade da situação que estava enfrentando, justamente por agravá-la (nem mesmo a paciente se "aguentava"). Essa avaliação (negativa) e de caráter afiliativo age como um insumo para Francine prosseguir com sua narrativa, concordando com o médico no turno seguinte (linha 134, "nem eu me aguentava"). Nas linhas 134-137, Francine continua sua narrativa (e sua prestação de contas) 
7 "As formulações trabalham a favor do entendimento entre os interlocutores. Assim, a atividade de formular é um método usado pelos participantes para mostrar ao outro o seu entendimento daquilo que foi tratado ou realizado no turno ou nos turnos anteriores, explicitado justamente para obter uma resposta do interlocutor que se traduz na decisão de confirmar ou desconfirmar o proposto pelo autor da formulação." (OSTERMANN; SOUZA, 2011). atribuindo, e ao mesmo tempo justificando, sua irritabilidade ao tratamento do câncer, período no qual ela menciona que teve que "segurar" muita coisa, referindo-se ao seu estado emocional perante os acontecimentos da época. O médico alinha-se com essa construção elaborando uma formulação de entendimento ${ }^{7}$ sobre o que Francine reporta: ela "se concedeu a oportunidade" de não mais segurar suas emoções.

No turno seguinte, ela continua prestando contas ao demonstrar que a procura de uma terapeuta não se deu de forma leviana, mas somente depois de analisar a situação, que relata estava ficando cada vez mais difícil. A decisão da paciente recebe afiliação do médico ao ser positivamente avaliada por ele em seu turno seguinte ("ótimo"). Francine, então, no próximo turno, continua prestando contas para o fato de ter experienciado desequilíbrio emocional, explicando que a opinião da médica consultada é a mesma, ou seja, essa médica também atribui o desequilíbrio emocional de Francine ao tratamento pelo qual ela teve que passar, e essa ideia ganha explícita afiliação de Sílvio com mais uma avaliação positiva concordando com ela no turno seguinte ("totalmente dentro do razoável", linha 152). Observe-se também, a partir da linha 153, a explicação de que a terapeuta em questão entende que esse medicamento será utilizado por um período de tempo limitado, o que aqui corrobora a imagem que Francine está construindo - com o aval do médico: a de que não é uma pessoa que, em uma situação de normalidade (i.e. se não tivesse vivenciado emoções ruins com a experiência do câncer), precisaria desse remédio em sua vida.

Pode-se considerar que, por meio dessas várias prestações de contas, Francine demonstra que relatar que está tomando um medicamento psicotrópico é uma ação delicada para ela. Por delicada entendemos a ação como envolvendo uma gama de aspectos com os quais a falante em questão tem que lidar, como: (a) o tópico em si que pode ser delicado para ela (contar a novidade sobre o psicotrópico ao médico); (b) uma possível ação despreferida do médico em resposta (se ele, por exemplo, tivesse produzido uma avaliação negativa ao seu relato); (c) o posicionamento do relato (logo após o médico iniciar um projeto de fechamento de sequência); e (d) a situação atual da saúde de Francine (ela já está tomando vários medicamentos e 
está em vias de apresentar mais um ao médico - que justamente já tinha avaliado serem muitos os remédios de que ela faz uso).

Além disso, é por meio das prestações de contas (em formato narrativo) que Francine realiza o delicado (porque requer uma ratificação do outro) e interessante trabalho de descrição de atividades atreladas a certas categorias (SACKS, 1992), aqui a uma categoria em especial, a de pessoa normal, em contraposição à pessoa com problemas emocionais. Assim, analisar a situação, procurar um terapeuta, reconhecer que nem ela mesma "se aguentava", atribuir sua irritabilidade a eventos passados que ela não podia controlar (o tratamento do câncer), não ter sido considerada uma pessoa depressiva pela própria terapeuta, dentre outras atividades, estão ligadas à normalidade da sua situação, ao indicializar, pontuar e construir o significado de "ser normal" ao contrário de ser anormal ou possuir de fato um problema emocional nesse contexto (CANGUILHEM, 2002; SEGER, 2007). O médico, por sua vez, coconstrói com a paciente as descrições dessas atividades como atreladas à normalidade ao prover continuadores, em especial, a avaliação negativa em concordância linhas 132-133. Também ao prover um riso (na linha 138) ao iniciar o turno que marca seu entendimento de que a paciente se "concedeu a oportunidade" de explodir (note-se que uma concessão é algo que se faz por vontade ou agência própria, o que deflagra um agir sobre algo, mais do que apenas se deixar levar) e as avaliações positivas "ótimo", na linha 145, "cla:ro (.) totalmente dentro do razoável" na linha 151152 e o entendimento de que é "um período" (linha 159). Essas contribuições do oncologista projetam um não-estranhamento das atitudes de Francine. Pelo contrário, afiliam-se à narrativa da paciente ao evidenciá-las como pertencentes a uma normalidade esperada para o momento da vida que ela está passando. Além disso, as contribuições do médico validam a narrativa de Francine e ratificam então a normalidade dos fatos narrados.

Esse cuidado de Francine em sua narrativa pode indicar que ela está lidando com a possibilidade de uma imagem se criar sobre ela a partir de tal relato, a de pessoa com desequilíbrio emocional, dependente de medicamento para viver "normalmente" em sociedade. Assim, Francine parece lidar o tempo todo em seu relato com uma tensão entre o que se pode considerar normal, esperado de uma paciente que tratou 
um câncer de mama, e o que constituiria um desvio do normal em um caso como esse.

Observa-se, também, que as prestações de contas providas pela paciente Francine não são requisitadas por seu interlocutor. Em outras palavras, o médico não pede, em nenhum de seus turnos, um motivo, um porquê. Ademais, também não se tratam de respostas "despreferidas" (POMERANTZ, 1984), como uma rejeição a uma oferta ou convite, por exemplo, que são ações que tendem a ser seguidas por prestação de contas quando rejeitadas. São prestações de contas, como demonstrado aqui e referido por Ostermann e Carvalho (2012) e Carvalho (2012), "sequencialmente não relevantes" - pelo menos não relevantes para a sequência que se instaurou até aquele momento. Contudo, são prestações de contas que se tornam sequencialmente relevantes no momento em que renovaram o contexto interacional e passaram a solicitar do médico um tipo de alinhamento.

Sendo assim, retomando aqui a análise em questão, toda a sua narrativa sobre o porquê do medicamento psicotrópico não fora requisitada. Portanto, em parte, podemos considerar as prestações de contas de Francine como um trabalho interacional que age em favor de um aspecto não explicitamente topicalizado pelos interagentes, a construção da situação de Francine como dentro de uma normalidade.

Entretanto, não podemos deixar de pontuar também que, apesar de agir em favor de um aspecto a princípio sequencialmente não relevante (se compararmos com o contexto do estudo referido), a construção da normalidade da situação de Francine recebe reconhecimento do médico (e, acima de tudo, é coconstruída por ele) quando ele concorda com ela e provê avaliações que são de caráter afiliativo em seus turnos. Dessa forma, concordamos com o entendimento explicitado por Firth (1995) de que as prestações de contas foram em sua maior parte consideradas na literatura como moldadas pelo contexto (context-shaped), sem terem sido encaradas também como renovadoras do contexto (context-renewing). Parece bastante palpável nessa interação o fato de que a narrativa da paciente via prestação de contas cria um contexto em que ações do médico se fazem necessárias a partir dali (afiliações ou não), e remediam a interação a partir dali (uma normalidade é então projetada pela falante e coconstruída e assegurada pelo 
interlocutor), não lidando apenas com algo prévio (a lista de medicamentos que a paciente deve prover).

Narrar, prestar contas: para quê?

Neste artigo, analisaram-se prestações de contas que agem prospectivamente na construção moral e identitária de uma paciente. As prestações de contas são então consideradas como uma atividade que requer uma atenção maior do analista: as ações que performam podem não se circunscrever à sequência construída pelos falantes até a prestação de contas em si, e sim a partir dali, agindo de maneira criativa e renovadora do contexto local. Conforme Firth (1995) afirma, esse entendimento foi pouco estudado na literatura sobre as prestações de contas. Ainda que esse texto de Firth seja de 1995, os estudos interacionais produzidos desde então ainda tendem a negligenciar essa dimensão das prestações de contas. Ou seja, chamamos a atenção aqui para outras dimensões sobre as quais as prestações de contas agem nas interações, suas consequências para a interação e novo contexto interacional que elas criam - o que se chama de característica context-renewing (renovadora de contexto) (HERITAGE; MAYNARD, 2006).

Além disso, considera-se que prestações de contas constituem uma atividade que lida com situações (e ações) delicadas e envolve fatores que requerem cuidado interacional dos falantes, tais como: (a) o tópico em si que pode ser delicado; (b) uma possível ação despreferida do interlocutor em resposta; (c) o posicionamento da prestação de contas na estrutura geral da interação; e (d) a construção de moralidade e normalidade da paciente.

Há que se refletir também que até mesmo a ordem em que a paciente reporta os nomes dos medicamentos que está consumindo revela tal delicadeza, bem como um trabalho de categorização por parte da paciente. Ela inicia pelos mais comuns, que atendem a problemas de ordem fisiológica e que são de conhecimento prévio do médico (i.e. o remédio para hipertensão e o hormônio da tireoide). Na sequência, lista o que seria um pouco mais problemático, por poderem ser vinculados a práticas de cuidado em saúde sobre as quais a própria paciente tem ingerência (como o consumo de alimentos ricos em açúcar e colesterol), mas ainda assim já de conhecimento do médico (i.e. os medicamentos para diabetes e colesterol elevado). É apenas então que menciona o remédio para dormir, e aqui 
especula-se que o relato do uso desse medicamento apenas não é mais problemático nesse contexto, pois também já era de conhecimento do médico. Vale lembrar que no momento da interação os participantes estão envolvidos em repassar a sua lista de medicamentos, ou seja, não há nada novo ali - a própria tentativa do médico de encerrar a sequência de retomada na linha 120, após tais medicamentos, nos aponta isso. É justamente a apresentação do novo medicamento - o antidepressivo - que é alocada como última nessa lista e abre uma nova sequência, uma narrativa que toma boa parte da interação.

Como fica evidente nos dados, a ordem dos medicamentos revela a sua categorização por Francine, como em um continuum de normalidade: os do primeiro grupo (para problemas fisiológicos) seriam os mais "comuns" ou "normais" de serem consumidos e cujas indicações envolvem pouca ou praticamente nenhuma ingerência da paciente para a necessidade de seu uso; os do segundo grupo (para diabetes e colesterol) envolvem sua ingerência em certo nível, já que hábitos considerados "não saudáveis" de um ponto de vista biomédico podem ter acarretado a necessidade de seu uso; e os do terceiro grupo (para problemas emocionais), que seriam, a princípio, pelo senso comum, aqueles que denotam ou podem denotar uma fraqueza emocional do indivíduo, uma falta de capacidade em lidar com a vida cotidiana - por analogia, uma "anormalidade", novamente, ressaltamos, no entendimento do senso comum.

Baseando-se em Gabe, Coveney e Williams (2015), especula-se aqui a possibilidade de a paciente em questão, nos dados analisados no presente artigo, associar o uso de um antidepressivo a uma fraqueza - como a adição seria no contexto de alguém necessitar de um hipnótico para dormir -, revelando assim um repertório moral em consonância com um dos relatados no estudo citado, o do paciente merecedor. $\mathrm{Ou}$ seja, a pessoa que justifica o uso do psicotrópico em função de um problema, uma dificuldade pela qual passa ou passou, que legitima a necessidade da ajuda do medicamento.

Assim, por meio deste artigo, além de chamarmos a atenção para a relação entre narrativas não sequencialmente solicitadas, normalidade e moralidade, objetivamos também chamar a atenção dos profissionais de saúde sobre o próprio valor da escuta das narrativas produzidas pelas pacientes nos consultórios médicos e sobre as ações interacionais que essas 
narrativas podem estar desempenhando ali. Na interação analisada, a prestação de contas na narrativa produzida mostra que há uma preocupação da paciente em construir-se como normal e legitimar-se como merecedora do medicamento. A atenção que o médico disponibiliza à narrativa e o fato de ele ratificar os turnos da paciente mostram que ele está orientado a promover também a saúde emocional da sua paciente oncológica.

\section{REFERÊNCIAS}

BUTTNY, R.; MORRIS, G. Accounting. In: ROBINSON, W.; GILES, H. (eds). The new handbook of language and social psychology. New York: John Wiley and Sons, 2001. p. 285-302.

CANGUILHEM, G. O Normal e o Patológico. Rio de Janeiro: Forense Universitária, 2002. 305p.

CARVALHO, T. O trabalho interacional de provimento de justificativas no Disque Saúde (AIDS). Dissertação de Mestrado. Programa de Pós-Graduação em Linguística Aplicada. Mestrado em Linguística Aplicada. Universidade do Vale do Rio dos Sinos - Unisinos, 2012.

COULON, A. Etnometodologia. Petrópolis: Vozes, 1995.

DE FINA, A. Narratives in interview. The case of accounts: for an interactional approach to narrative genres. Narrative Inquiry, v. 19, n. 2, p. 233-258, 2009.

DEL CORONA, M. O.; OSTERMANN, A. C. “Eu não aguento mais!": a produção de accounts narrativos nas ligações para o serviço de emergência da Brigada Militar (190). Calidoscópio, v. 11, n. 2, p. 178-191, 2013.

DENVIR, P. When patients portray their conduct as normal and healthy: An interactional challenge for thorough substance use history taking. Social Science \& Medicine, v. 75, p. 1650-1659, 2012.

DREW, P. Complaints about transgressions and misconduct. Research on Language and Social Interaction, v. 31, n. 3-4, p. 295325, 1998.

DREW, P;; HERITAGE, J. Talk at Work. Cambridge: Cambridge University Press, 1992. 
FIRTH, A. Accounts in negotiation discourse: a single-case analysis. Journal of Pragmatics, v. 23, p. 199-226, 1995.

GABE, J.; COVENEY, C.; WILLIAMS, S. Prescriptions and proscriptions: moralising sleep medicines. Sociology of Health and Illness, 2015, doi: 10.1111/1467-9566.12383.

GARCEZ, P. M. A perspectiva da Análise da Conversa Etnometodológica sobre o uso da linguagem em interação social. In: LODER, L. L.; JUNG, N. M. (Orgs.). Fala-em-interação social: uma introdução à Análise da Conversa Etnometodológica. Campinas, SP: Mercado de Letras, 2008. p. 17-38.

HERITAGE, J. Explanations as accounts: a conversation analytic perspective. In: ANTAKI, C. (Ed.). Analyzing lay explanation: a case book of methods. London: Sage, 1988. p. 127-144.

HERITAGE, J. Maintaining institutional realities. In: HERITAGE, J. Garfinkel and Ethnomethodology. Cambridge: Polity Press, 1984. p. 179-232.

HERITAGE, J. The epistemic engine: sequence organization and territories of knowledge. Research on Language and Social Interaction, v. 45, n. 1, p. 30-52, 2012.

HERITAGE, J.; MAYNARD, D. W. Communication in medical care: interaction between primary care physicians and patients. Cambridge: Cambridge University Press, 2006. 488 p.

HEWITT, J. P.; STOKES, R. Disclaimers. American Sociological Review, v. 40, n. 1, p. 1-11, 1975.

JEFFERSON, G. Transcript notation. In: ATKINSON, J.; HERITAGE, J. Structures of social action: studies in conversation analysis. New York: Cambridge University Press, 1984. p. ix-xvi.

JEFFERSON, G. On the sequential organization of troubles talk in ordinary conversation. Social Problems, v. 35, n. 4, p. 418-442, 1988.

LABOV, W. Some further steps in narrative analysis. Tradução de Waldemar Ferreira Netto. The Journal of Narrative and Life History, v. 7 (1/4), 1997. 
LINDSTRÖM, A., SORJONEN, M. Affiliation in conversation. In: SIDNELL, J.; STIVERS, T. (Eds.) The Handbook of Conversation Analysis. Wiley-Blackwell, 2013. p. 350-369.

OSTERMANN; A. C.; CARVALHO, T. O trabalho interacional de provimento de justificativas no Disque Saúde (AIDS). Comunicação pessoal. 2012.

OSTERMANN, A. C.; SOUZA, J. de. As demandas interacionais das ligações para o disque saúde e sua relação com o trabalho prescrito. Alfa: Revista de Linguística (UNESP. São José do Rio Preto. Online), v. 55, p. 135-162, 2011.

POMERANTZ, A. Agreeing and disagreeing with assessments: some features of preferred/dispreferred turn shapes. In: ATKINSON, J. M.; HERITAGE, J. Structures of social action: studies in conversation analysis (Studies in emotion and social interaction). Paris: Cambridge University Press, 1984. p. 57-101.

SACKS, H. Lectures on conversation. Oxford: Blackwell, 1992. v. 1 e v. 2.

SACKS, H. On doing "being ordinary". In: ATKINSON, J. M.; HERITAGE, J. Structures of Social Action: Studies in Conversation Analysis. Cambridge, UK: Cambridge University Press, 1984 [2007]. Trad. de Felipe Portela, Priscilla Pellegrino e Vívian Gomes.

SACKS, H.; SCHEGLOFF, E.; JEFFERSON, G. The simplest systematics for turn-taking in conversation. Language, v. 50, n. 4, p. 696-735, 1974.

SCHEGLOFF, E. Sequence Organization in Interaction: A Primer in Conversation Analysis I. New York: Cambridge University Press, 2007.

SCOTT, M. B.; LYMAN, S. Accounts. American Sociological Review, v. 33, n. 1, p. 46-62, Feb. 1968. Disponível em: <http:// jthomasniu.org/class/Stuff/PDF/ accounts.pdf >. Acesso em: 11 maio 2014.

SEGER, K. A construção da normalidade em consultas pediátricas. Dissertação de Mestrado. Mestrado em Linguística Aplicada. 
Programa de Pós-Graduação em Linguística Aplicada, Unisinos. São Leopoldo, 2007. 138p.

SELL, M.; OSTERMANN, A. C. Tensionando identidades de gênero e de sexualidade na fala-em-interação: o colapso discursivo da masculinidade homogênea. In: OSTERMANN, A. C.; MENEGHEL, S. N. Humanização. Gênero. Poder: Contribuições dos estudos de fala-em-interação para a atenção à saúde. Rio de Janeiro/São Paulo: Fiocruz e Mercado de Letras, 2012. p. 133-149.

SOUZA, J. de. Da impossibilidade de certezas na fala-em-interação em consultas de câncer de mama. Tese de Doutorado. Doutorado em Linguística Aplicada. Programa de Pós-Graduação em Linguística Aplicada, Unisinos. São Leopoldo, 2015. 198p.

SOUZA, J. de.; OSTERMANN, A. C. Glossário conciso de termos de estudos de fala-em-interação. In: OSTERMANN, A. C.; MENEGHEL, S. N. Humanização. Gênero. Poder: Contribuições dos estudos de fala-em-interação para a atenção à saúde. Rio de Janeiro/São Paulo: Fiocruz e Mercado de Letras, 2012. p. 163-165.

STEENSIG, J. Conversation Analysis and Affiliation and Alignment. In: MORTENSEN, K.; WAGNER, J. The Encyclopedia of Applied Linguistics: Conversation Analysis. Cambridge, UK: Wiley-Blackwell, 2012.

STERPONI, L. Account episodes in family discourse: The making of morality in everyday interaction. Discourse Studies, v. 5, n. 1, p. 79-100, 2003.

STIVERS, T. Stance, Alignment, and Affiliation During Storytelling: When Nodding Is a Token of Affiliation. Research on Language and Social Interaction, v. 41, n. 1, p. 31-57, 2008.

STIVERS, T.; HAYASHI, M. Transformative answers: One way to resist a question's constraints. Language in Society, v. 39, n. 1, p. 1-25, 2010.

STIVERS, T.; HERITAGE, J. Breaking the sequential mold: Answering "more than the question" during comprehensive history taking. Text, v. 21, p. 151-185, 2001. 


\section{Abstract \\ Why to explain? Normality constructed through language in oncological consultations}

This paper analyzes the activity of providing accounts, which involves social actions (ways of acting through talk-in-interaction) performed by a breast cancer patient in a follow-up consultation with her oncologist. The data analyzed is part of a corpus of 20 audiorecorded consultations in 2012 and 2014 between oncologists and breast cancer patients in a private hospital located in Southern Brazil. The interactions were transcribed and analyzed through the theoretical-methodological approaches of Conversation Analysis and Membership Categorization Analysis (SACKS, 1992). The central point consists in demonstrating how the accounts provided by the patient transform (in the sense of renewing) the interactional context when they solicit affiliation from the doctor and, as a consequence, construct the normality of the situation experienced by the patient. The sequential analysis evidences the social actions and the interactional consequences that an unsolicited instance of storytelling can generate not only to the sequential environment itself, but also to the reestablishment and reconstitution of the normality and the moral order, in a broader sense.

Keywords: oncology consultations; accounts; normality; morality; storytelling. 